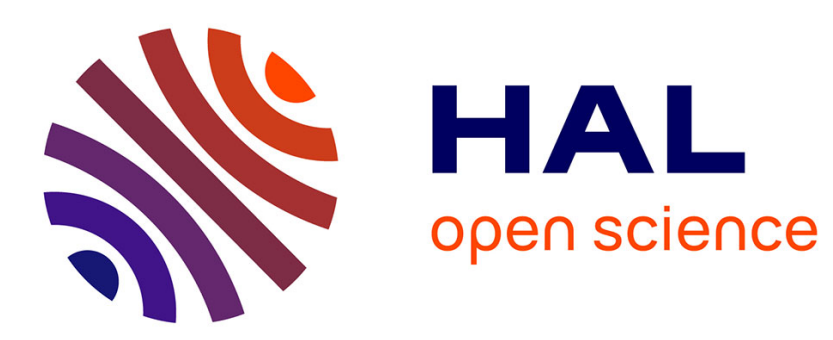

\title{
Probability gains of an epidemic-type aftershock sequence model in retrospective forecasting of $\geq 5$ earthquakes in Italy
}

R. Console, M. Murru, G. Falcone

\section{- To cite this version:}

R. Console, M. Murru, G. Falcone. Probability gains of an epidemic-type aftershock sequence model in retrospective forecasting of $\geq 5$ earthquakes in Italy. Journal of Seismology, 2009, 14 (1), pp.9-26. 10.1007/s10950-009-9161-3 . hal-00535493

\section{HAL Id: hal-00535493 \\ https://hal.science/hal-00535493}

Submitted on 11 Nov 2010

HAL is a multi-disciplinary open access archive for the deposit and dissemination of scientific research documents, whether they are published or not. The documents may come from teaching and research institutions in France or abroad, or from public or private research centers.
L'archive ouverte pluridisciplinaire HAL, est destinée au dépôt et à la diffusion de documents scientifiques de niveau recherche, publiés ou non, émanant des établissements d'enseignement et de recherche français ou étrangers, des laboratoires publics ou privés. 


\title{
Probability gains of an epidemic-type aftershock sequence model in retrospective forecasting of $M \geq 5$ earthquakes in Italy
}

\author{
R. Console • M. Murru • G. Falcone
}

Received: 27 November 2007 / Accepted: 19 March 2009 / Published online: 13 May 2009

(C) Springer Science + Business Media B.V. 2009

\begin{abstract}
A stochastic triggering (epidemic) model incorporating short-term clustering was fitted to the instrumental earthquake catalog of Italy for event with local magnitudes 2.6 and greater to optimize its ability to retrospectively forecast 33 target events of magnitude 5.0 and greater that occurred in the period 1990-2006. To obtain an unbiased evaluation of the information value of the model, forecasts of each event use parameter values obtained from data up to the end of the year preceding the target event. The results of the test are given in terms of the probability gain of the epidemic-type aftershock sequence (ETAS) model relative to a time-invariant Poisson model for each of the 33 target events. These probability gains range from 0.93 to 32000 , with ten of the target events yielding a probability gain of at least 10 . As the forecasting capability of the ETAS model is based on seismic activity recorded prior to the target earthquakes, the highest probability gains are associated with the occurrence of secondary
\end{abstract}

R. Console · M. Murru ( $\varangle)$ · G. Falcone

Istituto Nazionale di Geofisica e Vulcanologia,

Rome, Italy

e-mail: murru@ingv.it

G. Falcone

Dipartimento di Scienze della Terra,

Messina University, Messina, Italy mainshocks during seismic sequences. However, in nine of these cases, the largest mainshock of the sequence was marked by a probability gain larger than 50 , having been preceded by previous smaller magnitude earthquakes. The overall evaluation of the performance of the epidemic model has been carried out by means of four popular statistical criteria: the relative operating characteristic diagram, the $R$ score, the probability gain, and the log-likelihood ratio. These tests confirm the superior performance of the method with respect to a spatially varying, time-invariant Poisson model. Nevertheless, this method is characterized by a high false alarm rate, which would make its application in real circumstances problematic.

Keywords Epidemic-type aftershock sequence (ETAS) - Short-range forecasting model in Italy

\section{Introduction}

When earthquakes strike a populated area, authorities, mass media, and, more generally, people ask seismologists to forecast possible strong seismic activity for the near future. Up to the recent past, seismologists were accustomed to reply to these questions basing their judgments just on their personal experience and a bit of good sense rather than on quantitative assessment. 
Basically, in their replies, they were accustomed to declare that subsequent felt earthquakes are possible, but very unlikely to be stronger than the previous ones. Events occurring in the recent past in Italy have demonstrated that judgments based only on simple common seismological sense may lead one to underestimate the likelihood of strong aftershocks or even larger mainshocks following the first onset of a seismic series. Earthquake sequences starting with foreshocks, as well as sequences containing doublets or multiplets of mainshocks, are not rare features of the Italian seismicity.

Recent seismological developments provide both physical and statistical models for the phenomenon of earthquake clustering, The interaction among earthquake sources can be physically justified by the modification in the stress field caused by a dislocation on a fault (see King et al. 1994; Harris and Simpson 1998; King and Cocco 2001 and references therein). This physical model has been extensively applied and tested in numerous papers published in the literature (Stein et al. 1997; Gomberg et al. 2000; Kilb et al. 2002; Nostro et al. 2005; Steacy et al. 2005, among many others). In order to model both the spatial pattern of seismicity and the temporal variation of the rate of earthquake production, the fault constitutive properties have to be taken into account. This has been the innovative idea of the Dieterich (1994) model, which couples the stress perturbations with the rate- and-state-dependent friction law characterizing the mechanical properties of a fault population. The rate-and-state model has been proposed as the key ingredient of approaches aimed at evaluating the change in earthquake probability after seismic rate changes caused by previous earthquakes (Toda and Stein 2003; Toda et al. 2005; Catalli et al. 2008). It has been also used in building a probabilistic forecast of large events caused by the earthquakes occurring nearby (Stein et al. 1997; Parsons and Dreger 2000; Parsons 2004).

Unlike any kind of physical modeling, the method adopted in the present study is based only on empirical relationships and statistical tools. It has, however, the advantage of needing only the information contained in seismic catalogs and the capability of being tuned on the characteristic features of specific seismic regions. For these reasons, it can be tested and validated on a large number of available data, allowing seismologists to provide information based on quantitative assessments of an ongoing seismic sequence. This quantitative assessment, which is distinct from traditional earthquake prediction, belongs to the class of synoptic forecasts (a very popular concept in weather forecasting). Synoptic forecasts are based on a simple application of statistics in which the seismicity is modeled as a stochastic point process. Statistical procedures allow one to estimate the chance of occurrence of a given outcome of this process.

Console and Murru (2001) and Console et al. (2003, 2006a) showed that a simple stochastic clustering epidemic-type aftershock sequence (ETAS) model exhibits a much higher likelihood than the time-invariant Poisson hypothesis. They tested this clustering model on real seismicity of Italy, California, Greece, and Japan through likelihoodbased methods. With the purpose of a prospective test of short-term forecasting of moderate and large earthquakes in Italy, we have applied this epidemic model to the instrumental database of shallow seismicity (July 1987-December 2006). The most important contribution to the information score achieved by short-term epidemic models derives commonly from their ability to forecast a large number of small aftershocks (Console and Murru 2001; Console et al. 2003). In this study, we examine their ability to forecast (in statistical sense) the impending occurrence of a medium-to-large $(M \geq 5)$ earthquake in a forward-retrospective way on a catalog of instrumental seismicity.

This study has been developed in the context of the S2 project (2005-2007) with the aim of testing the use of our technique to forecast the evolution of seismic sequences in Italy. In this respect, this study must be considered of methodological nature only. In fact, due to the high false alarm rate characterizing the forecasts based on the ETAS model in general, the application of such methods to real cases would turn out a very difficult decision-making problem. 


\section{Brief description of the earthquake occurrence probability model adopted}

In this study, we consider the short-term clustering properties of earthquakes and give a brief outline of an increasingly popular statistical method for modeling the interrelation of any earthquake with any other. The details can be found in Ogata (1998), Console and Murru (2001), and Console et al. (2003, 2006a, b, 2007). The method is based on algorithms pertaining to the ETAS model published by the team on international reviews. This model has been used in many studies to describe or forecast the spatio temporal distribution of seismicity and reproduce many properties of real seismicity (Ma and Zhuang 2001; Ogata 2001, 2004a, b, 2005, 2006a, b, 2007; Ogata et al. 2003; Ogata and Katsura 2006; Ogata and Zhuang 2006; Felzer et al. 2002; Helmstetter and Sornette 2002, 2003; Saichev and Sornette 2006; Zhuang et al. 2004, 2005). The expected occurrence rate density of earthquakes with magnitude $m, \lambda(x, y, t, m)$, at any instant of time and geographical point, is modeled as the sum of the independent, or timeinvariant "spontaneous", activity and the contribution of every previous event:

$$
\begin{aligned}
\lambda(x, y, t, m)= & f_{r} \mu_{0}(x, y) \beta e^{-\beta\left(m-m_{0}\right)} \\
& +\sum_{i=1}^{N} H\left(t-t_{i}\right) \times \lambda_{i}(x, y, t, m),
\end{aligned}
$$

where $\mu_{0}(x, y)$ is the rate density of the longterm average seismicity (herein after called the reference seismicity), $f_{\mathrm{r}}$ is the failure rate (fraction of spontaneous events over the total number of events) of the process, $H(t)$ is the Heaviside step function, and $\lambda_{l}(x, y, t, m)$ is a kernel function that depends on the magnitude of the triggering earthquake, the spatial distance from the triggering event, and the time interval between the triggering event and the time of interest. We factorize this function in three terms depending, respectively, on time, space, and magnitude, as:

$$
\begin{aligned}
\lambda_{i}(x, y, t, m)= & K \times h\left(t-t_{i}\right) \times \beta e^{-\beta\left(m_{i}-m_{0}\right)} \\
& \times f\left(x-x_{i}, y-y_{i}\right),
\end{aligned}
$$

where $K$ is a constant parameter, while $h(t)$ and $f(x, y)$ are the time and space distributions, respectively.

For the time dependence, we adopt the modified Omori law (Ogata 1983):

$h(t)=(t+c)^{-p}(p>1)$,

where $c$ and $p$ are characteristic parameters of the process.

The spatial distribution of the triggered seismicity is modeled by a function, with circular symmetry around the point of coordinates $\left(x_{i}, y_{i}\right)$. This function in polar coordinates $(r, \theta)$ can be written as:

$f(r, \theta)=\left[\frac{d_{i}^{2}}{\left(r^{2}+d_{i}^{2}\right)}\right]^{q}$

where $r$ is the distance from the point $\left(x_{i}, y_{i}\right), q$ is a free parameter modeling the decay with distance, and $d_{i}$ is the characteristic triggering distance. We assume that $d_{i}$ is related to the magnitude $m_{i}$ of the triggering earthquake and is proportional to the square root of its rupture area, as observed in real data (Kagan 2002):

$d_{i}=d_{0} 10^{0.5\left(m_{i}-m_{0}\right)}$,

where $d_{0}$ is the characteristic triggering distance of an earthquake of magnitude $m_{0}$.

The magnitude distribution of all earthquakes in a sample follows the Gutenberg-Richter law with a constant $\beta$ value, which is related to the most widely known $b$ value by the relationship $\beta=b \ln 10$.

Although the temporal aftershock decay may yield effects up to some years, or even tens of years in exceptional cases, this model is generally considered to be a short-term forecasting model because the effect of an earthquake on the subsequent seismicity rate is greatest immediately after the earthquake occurs.

Assuming an isotropic function for the spatial distribution of triggering effect might seem too simplistic because the theory of elasticity predicts that the Coulomb stress changes caused by slip on an earthquake source are azimuth-dependent, producing negative lobes of stress and seismicity 
shadows. In spite of these theoretical considerations, seismicity shadows are difficult to observe in practice. This can be explained, for instance, by small-scale stress heterogeneities on the fault plane (Marsan 2006; Helmestetter and Shaw 2006). Another circumstance that may apparently suppress azimuth dependence, especially in connection with triggering events of small magnitude, is the smoothing effect of the location errors, which, for the catalog of the Italian seismicity used in this study, are of the order of up a few kilometers. Last, but not less important is also the consideration that a full application of the physical model is practically impossible in the present context, because the focal mechanism is unknown for most of the earthquakes in our catalog.

To conclude this short description, we summarize that our model has a number of free parameters appearing in Eqs. 1, 2, 3, 4, and 5, the values of which can be estimated from an earthquake catalog using maximum likelihood techniques (Kagan 1991). The set of free parameters for the ETAS model actually estimated in this study are the following: $K$ (productivity coefficient), $c$ (time constant of the Omori-Utsu formula), $p$ (exponent of the Omori-Utsu formula), and $d_{0}$ (characteristic distance of the spatial kernel of triggered events). The value of $q$ (exponent of the spatial kernel of triggered events) has been fixed equal to 1.5 in this study in order to limit the number of free parameters in the learning phase and to make the inversion procedure more robust. This choice is in agreement with the asymptotic behavior of the theoretical stress change decay with the distance from the source. The failure rate, $f_{\mathrm{r}}$, is not included in the number of free parameters because its value is conditioned by the set of the other free parameters (the expected number of independent events divided by $f_{\mathrm{r}}$ must yield the long-term total number of earthquakes in the catalog). The $\beta$ (or $b$ ) value of the Gutenberg-Richter magnitude distribution is another parameter of the model, assumed constant over the geographical area spanned by the catalog, and obtained independently of the other free parameters. Finally, the grid of values defining the rate density space distribution $\mu_{0}(x, y)$ (Eq. 1) might be considered a set of free parameters, which are preliminarily determined from the analysis of the earthquake catalog for each learning phase. We use the seismic catalog collected by the Istituto Nazionale di Geofisica e Vulcanologia (INGV; Chiarabba et al. 2005) to estimate model parameter values. The model has been tested in a forward-retrospective way for earthquakes with $M_{1} \geq 5.0$ in Italy during 1990-2006. We test by computing the forecasted occurrence rate just before each target earthquake. For each target event, we use model parameter estimates based on data in the previous learning period and consider contributions from all earthquakes up to the year preceding the time of the target earthquake to compute forecasted rates.

\section{The Italian catalog and its completeness}

The database used (Chiarabba et al. 2005) covers the time period July 1987-2002. We have extended it to the most recent years by means of the bulletins of the instrumental seismicity published by the INGV (2007), obtaining a data set of 52,182 earthquakes of magnitude equal to or larger than 1.5. The largest recorded magnitude is $M_{\max }=$ 5.9. Before estimating the occurrence probability of the significant events, we have evaluated the spatial and temporal completeness of the instrumental database. Different techniques have been suggested to compute $M_{\mathrm{c}}$ (e.g., Ogata and Katsura 1993; Rydelek and Sacks 1989; Wiemer and Benoit 1996; Wiemer and Wyss 2000). Assuming self-similarity of the earthquake process, consequently implying a power-law distribution of earthquakes in the magnitude and in the seismic moment domain, a simple and frequently used technique for estimating $M_{\mathrm{c}}$ is based on the smallest magnitude for which this power law applies. This methodology, which delivers a good initial estimate, has been applied through the ZMAP software package (Wiemer 2001). Our analysis shows that this catalog can be considered complete for magnitudes equal to 2.1 and larger, which yields a total of 17,472 events (Fig. 1a). The maximum likelihood value for the $b$ parameter of the Gutenberg-Richter frequency-magnitude relation (FMD) is $0.878 \pm 0.006$, with the error computed using the formula suggested by Shi and Bolt (1982). To examine the average temporal $M_{\mathrm{c}}$ 

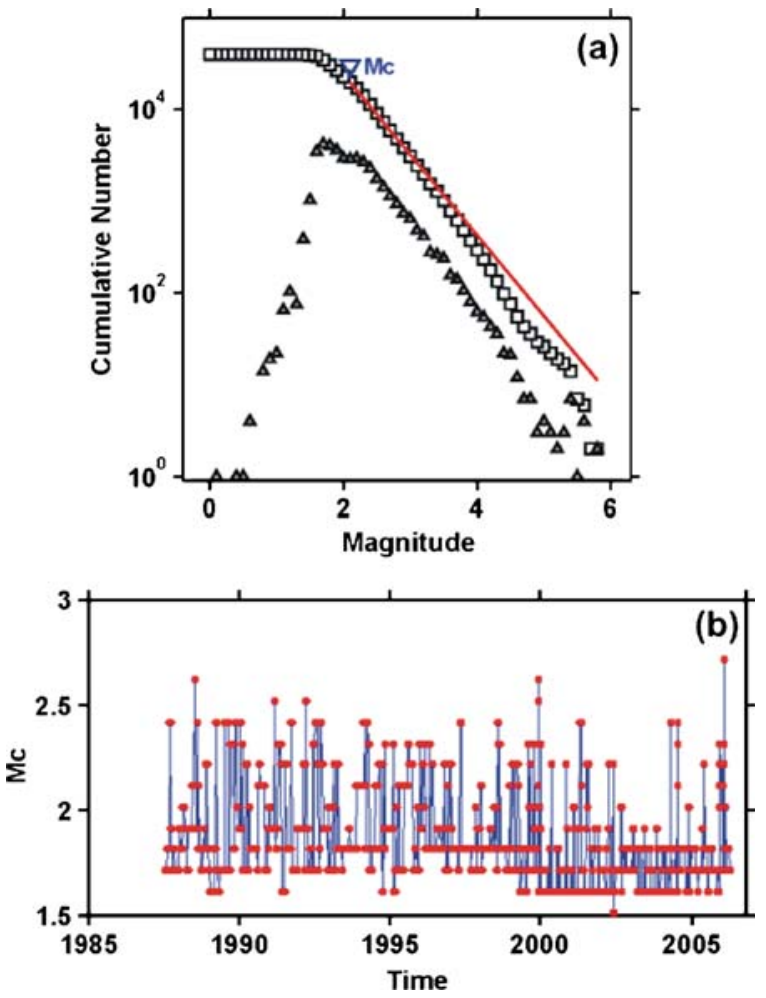

Fig. 1 a Frequency magnitude distribution for the Italian seismicity in the period 1987-2002. Triangles indicate the density distribution of the frequency-magnitude. The $b$ value is estimated by the maximum likelihood method. The $M_{\mathrm{c}}$ selected $\left(M_{\mathrm{c}}=2.1\right)$ is the magnitude at which $95 \%$ of the observed data can be modeled by a straight-line fit. b Temporal variation of $M_{\mathrm{c}}$ (minimum completeness magnitude) in the period July 1987 to December 2006. $M_{\mathrm{c}}$ was computed from $M_{1} 1.5$ for temporal windows, each containing 150 events and moving forward by steps of 50 events

trend by means of a one-dimensional approach, we apply a standard moving-window technique. Every temporal window contains 150 events, and it is moved forward by 50 events at each step. The $M_{\mathrm{c}}$ value in the plot vs. time spans from 1.5 to 2.6 (Fig. 1b). $M_{\mathrm{c}}$ appears equal to or smaller than 2.6 in all the samples of 150 events, except for the last one. This slightly higher magnitude threshold refers only to 150 events out of 9,000 . We have ignored this single case, probably due to the fact that the catalog was not yet ready in its reviewed final version at its very end.

In Fig. 2, we have mapped the minimum completeness magnitude using a sample size of $N=$ 100 and a node spacing of $10 \mathrm{~km}$. $M_{\mathrm{c}}$ varies from

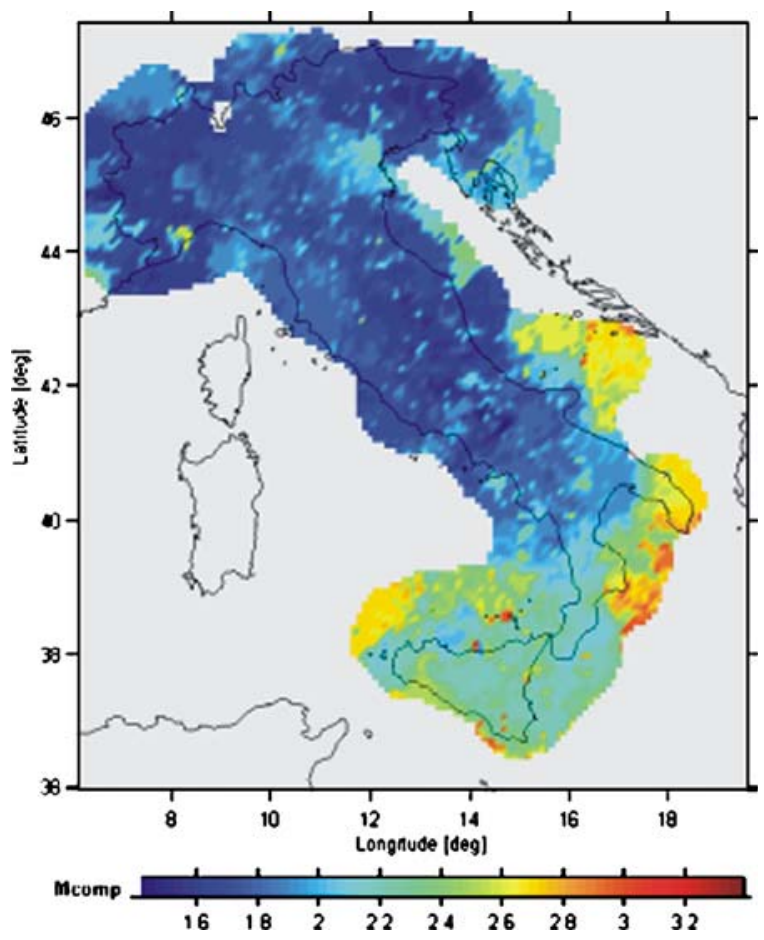

Fig. 2 Map of the spatial distribution of $M_{\mathrm{c}}$ computed by measuring the deviation from an assumed power law. $M_{\mathrm{c}}$ is the best combination among the $90-95 \%$ of confidence levels and the FMD maximum curvature. This map was obtained by fixing 100 earthquakes to nodes of a grid spaced $10 \mathrm{~km}$ apart. The sampling radii range between 5 and $40 \mathrm{~km}$

values near 1.5 in Central and Northern Italy to values of $M_{\mathrm{c}}=2.6$ to the south in Calabria and Sicily regions.

For the subsequent analysis, to use a uniform completeness magnitude for the Italian territory, we choose the conservative value of $M_{\mathrm{c}}=2.6$ within the geographical areas suggested by the spatial analysis (Fig. 2). There are 9,307 events from July 1987 to December 2006 that are above this completeness magnitude.

\section{Analysis and results}

Our main activity was focused on the computation of the occurrence probability for 33 shallow shocks $\left(M_{1} \geq 5.0\right)$ which occurred in the Italian region (adequately covered by the seismological network with a completeness magnitude $M_{\mathrm{c}}=$ 2.6) from 1990 to 2006, just some hours before 
they had occurred (Fig. 3 and Table 2). In order to quantify the expected occurrence rate density $\left(M_{1} \geq 5.0\right.$ events per day per square kilometer) before these target events, we fit our ETAS model to 17 different learning periods (Table 1) and their relative spatial distributions of the reference seismicity. In this way, the ETAS model has been tested retrospectively for these 33 events $\left(M_{1} \geq\right.$ 5.0) that occurred during the period under analysis, using only parameters value estimates obtained from data in the preceding learning phases, whose periods extend until the year before the considered shocks. The last column in Table 1 shows the number of target events in each year following its learning period.

We estimate the spatial distribution of the longterm reference seismicity by smoothing all the events above $M_{\mathrm{c}}$ by the method described by Console and Murru (2001), following Frankel
(1995), with a correlation distance of $20 \mathrm{~km}$. Figure 4 shows the smoothed seismicity in the Italian region for the July 1987-2001 period. The parameter estimates for each period are shown in Table 1. The minimum magnitude considered in each learning phase for the triggering and target events is 2.6 and 3.0, respectively.

The best fit algorithm, based on a step-by-step method, is quite robust, and it always converges on the same set of parameters within the approximations allowed by the computer, independently of the initial values adopted for the four free parameters. With respect to the stability of the results obtained from the best fit in relation to the different data sets given in input, the parameters obtained from the algorithm appear quite stable, starting from the shortest time interval (3 years with only 803 events) up to the longest (18 years with 8,015 events). This is particularly true for
Fig. 3 Epicentral map of earthquakes $(M \geq 5.0)$ which occurred in Italy from January 1990 to December 2006. The small gray dots show the epicenters of the earthquakes of smaller magnitude in the whole period July 1987-December 2006

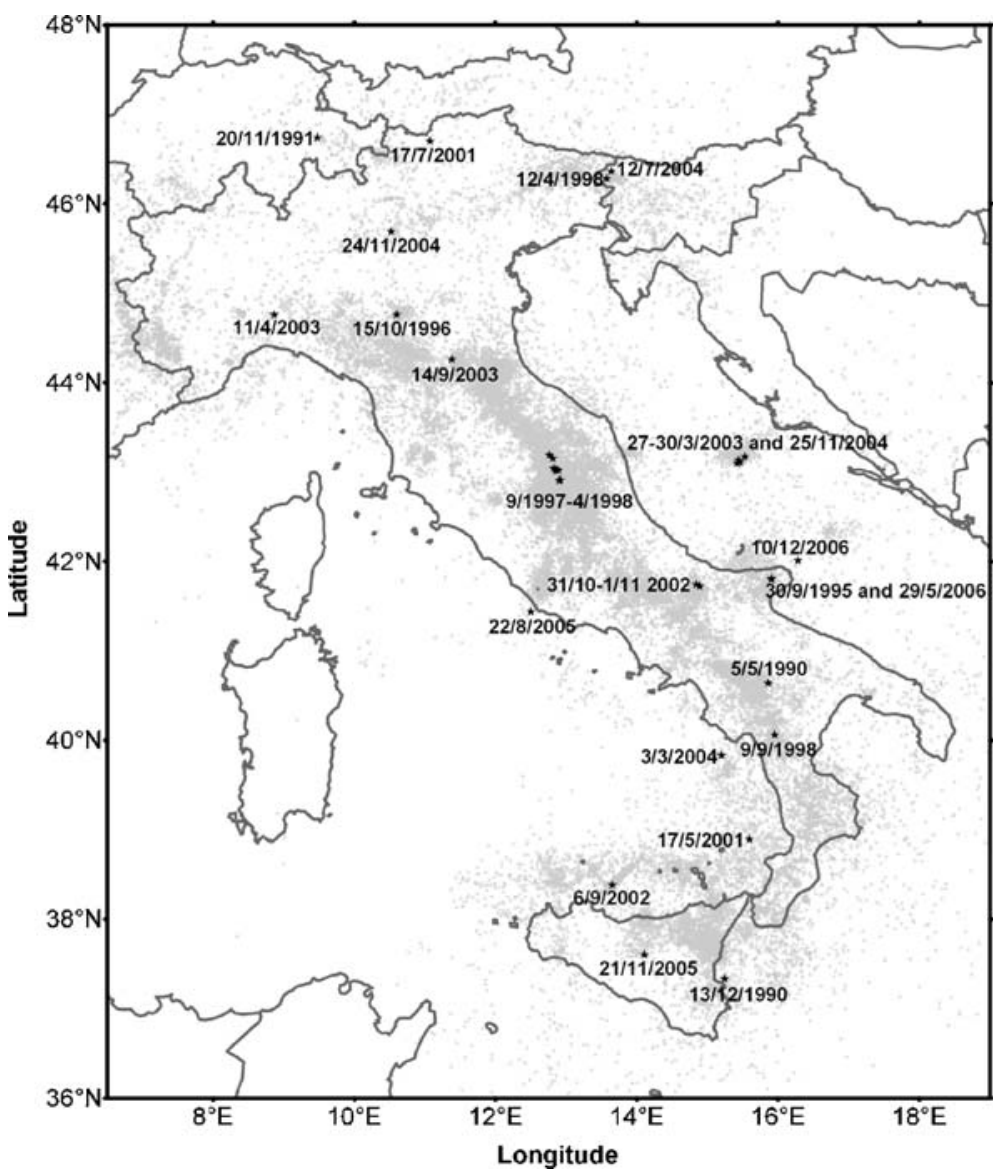


Table 1 Maximum log-likelihood parameters of the purely stochastic model (ETAS; learning phases)

\begin{tabular}{|c|c|c|c|c|c|c|c|c|}
\hline Time span & $\begin{array}{l}\text { Number of events } \\
(M \geq 2.6)\end{array}$ & $\begin{array}{l}K \\
\left(\text { days }^{\mathrm{p}-1}\right)\end{array}$ & $\begin{array}{l}d_{0} \\
(\mathrm{~km})\end{array}$ & $\begin{array}{l}c \\
\text { (days) }\end{array}$ & $p$ & $f_{\mathrm{r}}$ & dlog & $\begin{array}{l}\text { Target } \\
\text { events }\end{array}$ \\
\hline 01/07/1987-31/12/1989 & 830 & $2.36 \mathrm{E}-03$ & 0.84 & $1.75 \mathrm{E}-02$ & 1.16 & $5.91 \mathrm{E}-01$ & 396.09 & 2 \\
\hline 01/07/1987-31/12/1990 & 1,179 & $2.20 \mathrm{E}-03$ & 0.83 & $1.34 \mathrm{E}-02$ & 1.15 & $5.70 \mathrm{E}-01$ & 555.66 & 1 \\
\hline 01/07/1987-31/12/1991 & 1,523 & $2.02 \mathrm{E}-03$ & 0.87 & $1.05 \mathrm{E}-02$ & 1.12 & $5.59 \mathrm{E}-01$ & 574.25 & 0 \\
\hline 01/07/1987-31/12/1992 & 2,074 & $1.49 \mathrm{E}-03$ & 0.83 & $6.27 \mathrm{E}-03$ & 1.13 & $6.15 \mathrm{E}-01$ & 938.35 & 0 \\
\hline 01/07/1987-31/12/1993 & 2,136 & $1.56 \mathrm{E}-03$ & 0.82 & $6.09 \mathrm{E}-03$ & 1.12 & $6.01 \mathrm{E}-01$ & $1,037.84$ & 0 \\
\hline 01/07/1987-31/12/1994 & 2,465 & $1.56 \mathrm{E}-03$ & 0.79 & $6.38 \mathrm{E}-03$ & 1.11 & $5.96 \mathrm{E}-01$ & $1,233.25$ & 1 \\
\hline 01/07/1987-31/12/1995 & 2,802 & $1.60 \mathrm{E}-03$ & 0.80 & $6.78 \mathrm{E}-03$ & 1.10 & $5.91 \mathrm{E}-01$ & $1,393.48$ & 1 \\
\hline 01/07/1987-31/12/1996 & 3,164 & $1.47 \mathrm{E}-03$ & 0.82 & $7.17 \mathrm{E}-03$ & 1.08 & $5.84 \mathrm{E}-01$ & $1,597.84$ & 6 \\
\hline 01/07/1987-31/12/1997 & 4,156 & $2.20 \mathrm{E}-03$ & 0.74 & $5.67 \mathrm{E}-03$ & 1.06 & $5.51 \mathrm{E}-01$ & $1,956.87$ & 4 \\
\hline 01/07/1987-31/12/1998 & 4,737 & $4.43 \mathrm{E}-03$ & 0.49 & $6.76 \mathrm{E}-03$ & 1.08 & $4.67 \mathrm{E}-01$ & $3,719.56$ & 0 \\
\hline 01/07/1987-31/12/1999 & 5,116 & $1.41 \mathrm{E}-03$ & 0.83 & $6.10 \mathrm{E}-03$ & 1.00 & $7.03 \mathrm{E}-01$ & $3,086.16$ & 0 \\
\hline 01/07/1987-31/12/2000 & 5,578 & $3.84 \mathrm{E}-03$ & 0.51 & $7.16 \mathrm{E}-03$ & 1.09 & $4.73 \mathrm{E}-01$ & $4,256.07$ & 2 \\
\hline 01/07/1987-31/12/2001 & 5,955 & $3.48 \mathrm{E}-03$ & 0.53 & $7.30 \mathrm{E}-03$ & 1.09 & $4.86 \mathrm{E}-01$ & $4,392.75$ & 3 \\
\hline 01/07/1987-31/12/2002 & 6,558 & $3.48 \mathrm{E}-03$ & 0.55 & $7.35 \mathrm{E}-03$ & 1.09 & $4.80 \mathrm{E}-01$ & $4,612.22$ & 5 \\
\hline 01/07/1987-31/12/2003 & 7,147 & $5.84 \mathrm{E}-03$ & 0.42 & $1.03 \mathrm{E}-02$ & 1.10 & $4.34 \mathrm{E}-01$ & $6,289.64$ & 4 \\
\hline 01/07/1987-31/12/2004 & 7,486 & $1.22 \mathrm{E}-03$ & 0.89 & $1.41 \mathrm{E}-02$ & 1.10 & $4.85 \mathrm{E}-01$ & $6,258.86$ & 2 \\
\hline 01/07/1987-31/12/2005 & 8,015 & $4.82 \mathrm{E}-03$ & 0.45 & $9.43 \mathrm{E}-03$ & 1.10 & $4.40 \mathrm{E}-01$ & $6,830.34$ & 2 \\
\hline
\end{tabular}

The lower magnitude threshold of triggering and target events is 2.6 and 3.0, respectively. The exponent of the spatial distribution $(q)$ is 1.5 (fixed)

the $p$ (exponent of the Omori law) parameter. Noteworthy is a remarkable negative correlation between the $K$ and $d_{0}$ parameters. This is not surprising because both of them are related to the number of events triggered by an earthquake of given magnitude, with the difference that $d_{0}$, unlike $K$, also affects the spatial range of the triggered events. The $c$ parameter (constant of
Fig. 4 Smoothed seismicity of the Italian region for the July 1987-2001 period using $20 \mathrm{~km}$ as the value of the correlation distance. This distribution is obtained by a Gaussian smoothing of the catalog, following the method presented by Frankel (1995). The color scale represents the average number of earthquakes $(M \geq 2.6$ and $h \leq 70 \mathrm{~km}$ ) in an area of $1 \mathrm{~km}^{2}$ over the time period above reported

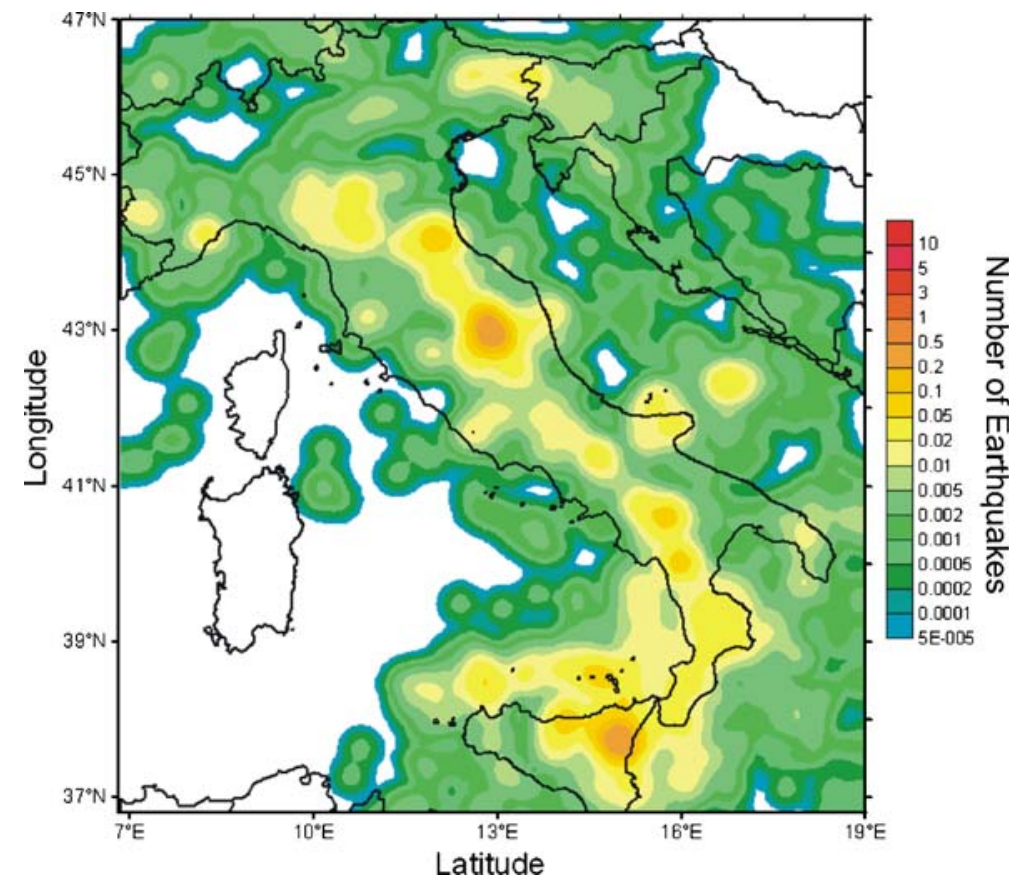




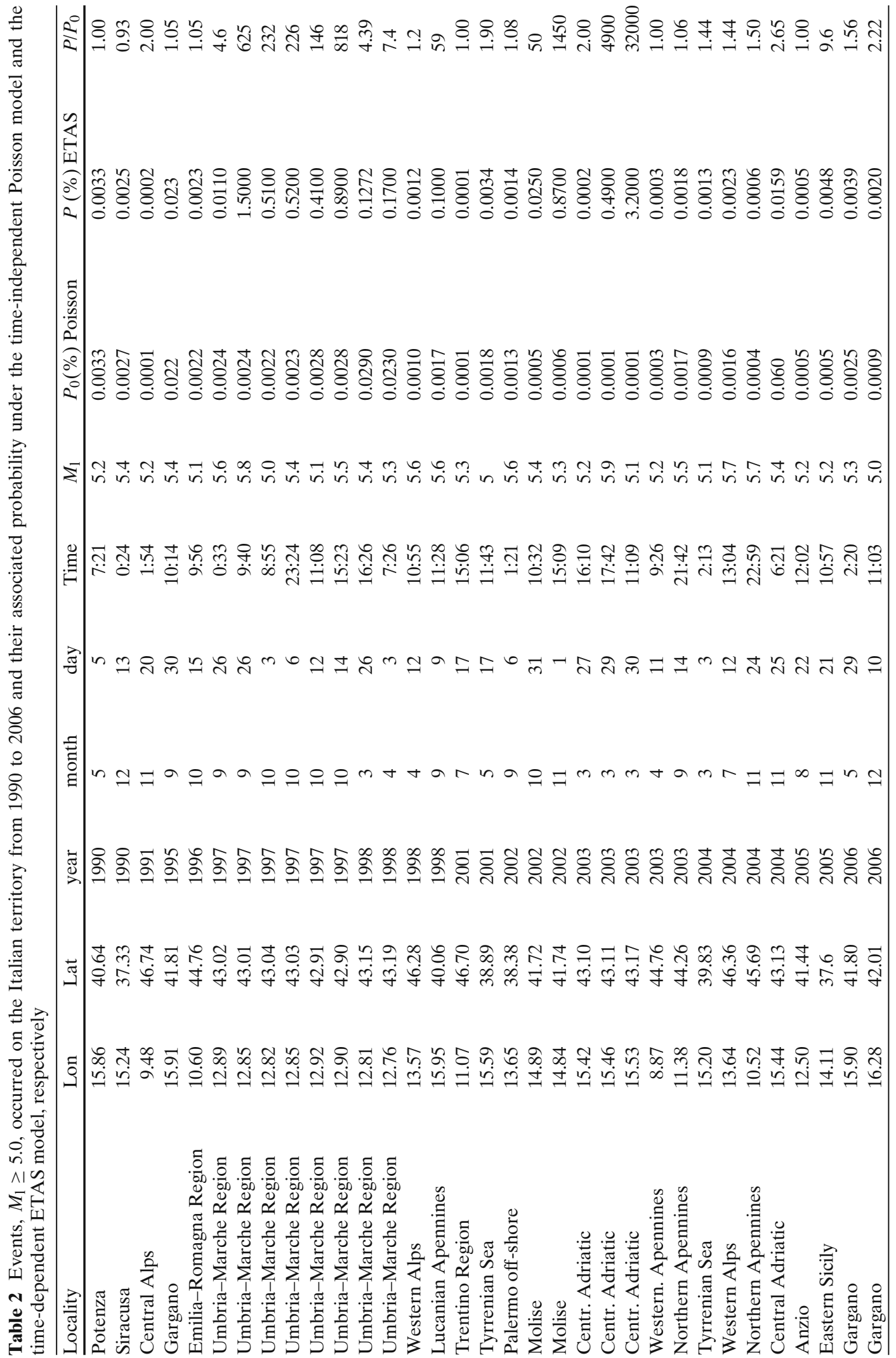


the Omori law) is stably larger than 0.0057 days (8 min) and smaller than 0.010 days (14 min), except for the first three learning periods for which it exhibits fairly larger values. Lastly, the $f_{\mathrm{r}}$ (failure rate) parameter ranges from 0.44 to 0.70 . That means that depending on the learning period of time, a fraction between $44 \%$ and $70 \%$ of the events appears to belong to the spontaneous seismicity, and conversely, a fraction between $30 \%$ and $56 \%$ must be regarded as triggered according to the model.

For the 33 forward-retrospective tests, we have considered as minimum magnitude for the triggering and target events $M_{1}=2.6$ and $M_{1}=5.0$, respectively. The expected occurrence rate density $\lambda$ for $M_{1} \geq 5.0$ target events has been translated into occurrence probability $P$ through the standard relationship

$$
\begin{aligned}
P & (E \mid \Delta X, \Delta Y, \Delta T, \Delta M) \\
& =1-\exp \left(-\int_{\Delta X, \Delta Y, \Delta T, \Delta M} \lambda(x, y, t, m) d x d y d t d m\right) .
\end{aligned}
$$

The 24-h probability is computed for circular areas within $30 \mathrm{~km}$ from the target event epicenters listed in Table 2. The probabilities are issued at 8.00 UTC or 20.00 UTC preceding the impending earthquake. These probabilities, reported in the last column of Table 2, range from less than $0.0001 \%$ to more than $6 \%$ according to the background seismicity and the activity preceding each target event in its proximity. For comparison, Table 2 reports also the occurrence probabilities under a time-invariant Poisson model based only on the smoothed seismicity rate. For 12 of these target events, the epidemic time-dependent model yields probabilities that are at least five times higher than the Poisson probabilities. In particular, eight of these events exhibit a probability gain of at least a factor of 100 .

\section{Statistical evaluation of the performance of the ETAS model}

In the previous section, we have shown that the forecast method based on the ETAS model achieves a high probability gain for a number of earthquakes with magnitude equal to or larger than 5.0 occurring in the Italian territory and surrounding regions from 1990 up to 2006. This is not enough to demonstrate that this method provides forecasts that are significantly more reliable than simple random forecasts.

In previous papers, we have applied the loglikelihood ratio criterion, comparing the performance of the time-dependent ETAS model with that of a time-independent, spatially variable Poisson model (Console et al. 2003, 2006a, b, 2007). The likelihood computation is possible for our ETAS model because forecasts are expressed by an occurrence rate density function defined at any point of space and time. Even if we have formerly stated that our epidemic model provides synoptic forecasts, and not predictions, in this paper, for measuring the effectiveness of our earthquake forecasting algorithm, we apply statistical techniques that are commonly used for testing earthquake prediction methods (Console 2001). These techniques are based on the observation of a sufficient number of past cases aiming at determining the rate at which the precursor has been followed (success rate) or not followed (false alarm rate) by the target seismic event, or the rate at which a target event has been preceded (alarm rate) or not preceded (failure rate) by the precursor. Four different statistical criteria have been adopted in this study: the first three of them are the relative operating characteristic (ROC) diagrams, the $R$ score and the overall probability gain. These methods evaluate the performance of the forecast model relative to a random chance using the approach of a binary forecast by considering the events (earthquakes) as being forecast either to occur or not to occur in every given time-space cell. The fourth method consists in the computation of the log-likelihood ratio. It does not refer to the issue of forecasts in binary form, but requires the computation of the occurrence probability for events in a discrete set of spatial cells and time bins. Details of the four methods are given in Appendix.

There is no general agreement on the superiority of a testing method with respect to another. For instance, Holliday et al. (2005) consider the ROC diagram method less subject to 
bias than the maximum likelihood test to evaluate the performance of a forecast model relative to random chance. Moreover, from theoretical and simulation results, Kagan (2007) deduced that the error diagram, related to the relative operating characteristic, is more informative than the likelihood ratio and uniquely specifies the information score.

Conversely, according to comments received from the reviewers of this and other papers, this statement is applicable only to specific situations and not to space-time-magnitude forecasting models in general. It is easy to see that in general, there may be an infinite number of different likelihood models, with different information scores, that would all have the same ROC diagram. Furthermore, neither the ROC nor the $R$ score methods can accommodate a spatially varying reference model, and therefore, they are not particularly informative.

The first step in the generation of the ROC diagrams for the verification of the probabilistic forecasting ETAS model is the construction of the $2 \times 2$ contingency tables with variable alarm thresholds.

The verification period of our model starts from the same date of the previous forwardretrospective test, 1 January 1990, and goes up to 31 December 2006. The Italian seismogenic region to be studied has been divided into a grid of $(12,221)$ square boxes of $10 \times 10-\mathrm{km}$ size, while the entire verification period is divided in 12,418 bins of $12 \mathrm{~h}$ each. In this way, the total number of space time cells amounts to 151,760,378. The minimum magnitude of the target events for which forecasts are considered was chosen equal to that of the previous test (5.0), for a total of 33 earthquakes. Note that the number of cells containing target events is only 32 because one cell contains two earthquakes (the two mainshocks of the Umbria-Marche 1997 sequences). For all the time bins included in each year, we have used the maximum likelihood parameters obtained from the time period up to the end of the previous year.

In order to fill the contingency tables, in this study, we define forecasts in time-space cells where the expected occurrence rate of earthquake with magnitudes greater than the lower cutoff magnitude (equal to 5.0) exceeds a given thresh-
Table 3 Contingency tables for the ETAS model from January 1, 1990 to December 31, 2006 for two values of the threshold occurrence rate value $(r)$ of, respectively, $1.00 \mathrm{E}-$ 07 and $1.00 \mathrm{E}-04$ events per day per $100 \mathrm{~km}^{2}$

\begin{tabular}{lllr}
\hline Observed & & & \\
\hline Forecast & Yes & No & \multicolumn{1}{c}{ Total } \\
\hline$r=1.00 \mathrm{E}-07$ & & & \\
Yes & $($ a $) 27$ & $($ b $) 30,016,051$ & $30,016,078$ \\
No & $(d) 5$ & $(c) 121,744,295$ & $121,744,300$ \\
Total & 32 & $151,760,346$ & $151,760,378$ \\
$r=1.00 \mathrm{E}-04$ & & & \\
Yes & $($ a $) 7$ & $(b) 7,992$ & 7,999 \\
No & $(d) 25$ & $(c) 151,752,354$ & $151,752,379$ \\
Total & 32 & $151,760,346$ & $151,760,378$ \\
\hline
\end{tabular}

old value $r$. Table 3 shows the results for two contingency tables obtained for the occurrence rate thresholds of $1.00 \mathrm{E}-07$ and $1.00 \mathrm{E}-04$ (events per day per $100 \mathrm{~km}^{2}$ ), respectively.

Note the extraordinarily large number of cells without target events with respect to those with them. Note also that a threshold $r=1.00 \mathrm{E}-07$ has been exceeded in about $20 \%$ of the target spacetime volume, including 27 out of 32 events. Conversely, a threshold 1,000 times higher has been exceeded in about $0.0053 \%$ of the total number of cells, including only seven out of the 32 events, but with a much higher probability gain.

Varying the threshold value for the verification of ETAS forecast, we have obtained the values of the hit rate $H$ and false alarm rate $F$ to be used for the preparation of the ROC diagram for the given magnitude threshold of the target events (see Appendix for their definitions). The results are summarized in Fig. 5.

This figure show that the curve of the ROC diagram for the ETAS model is well above the diagonal linking the points $(0,0)$ and $(1,1)$, denoting a non-random positive correlation between the forecasts and the earthquake occurrence.

Figure 6 show the plots for the $R$ score versus the false alarm rate $(F)$ according to the definition adopted by Shi et al. (2001). The $R$ score ranges from 0.03 to 0.65 when the false alarm rate increases from $1.0 \mathrm{E}-06$ to 0.2 , decreasing the alarm threshold from $1.0 \mathrm{E}-03$ to $1.0 \mathrm{E}-07$ events per day per $100 \mathrm{~km}^{2}$. These results confirm the non-random behavior of the forecasts based on the ETAS model. 


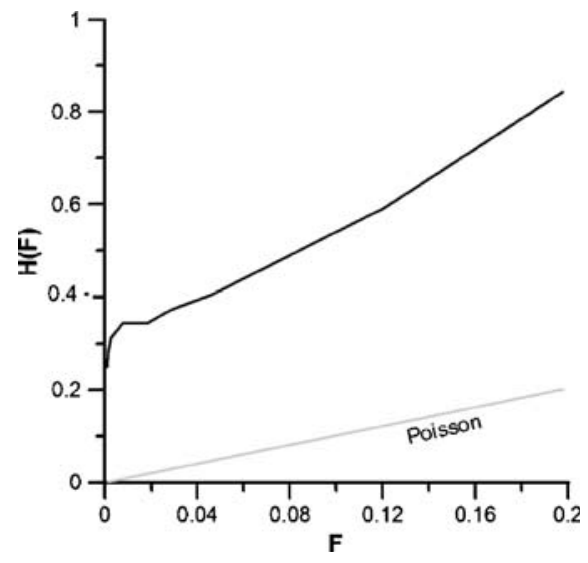

Fig. 5 Values of the hit rate $H$ (fraction of "hotspot" cells that have an earthquake forecast over the total number of cells with actual earthquakes) versus the false alarm rate $F$ (the fraction of the forecast cells that do not have earthquakes over the total number of cells with no actual earthquakes in them). Each value of $F$ corresponds to a different threshold rate for issuing alarms

The same contingency tables have also allowed the computation of the respective values of the probability gain $G$, defined by Aki (1981) as the ratio between the conditional and the unconditional rate. The results for $G$ are plotted versus the false alarm rate $F$ in Fig. 7 . The probability gain ranges from values of some units to several tens of thousands when the false alarm rate decreases from 0.2 to $1.0 \mathrm{E}-06$, increasing the alarm

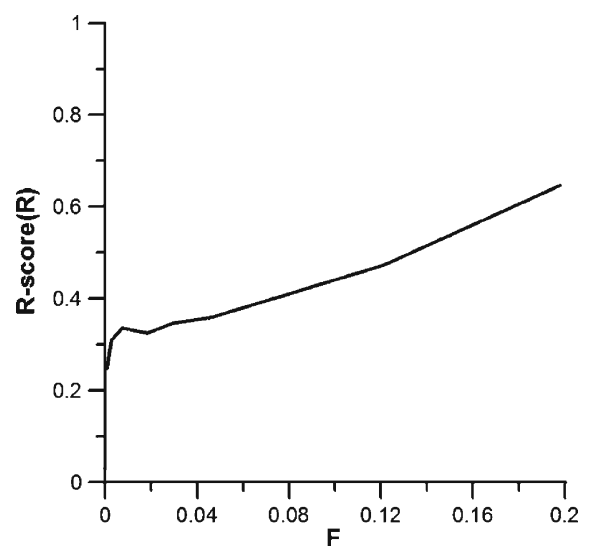

Fig. 6 As in Fig. 5, for the $R$ score (number of cells in which earthquakes are successfully predicted/total number of cells in which earthquakes occur) - (number of cells with false alarms/total number of cells without any earthquakes)

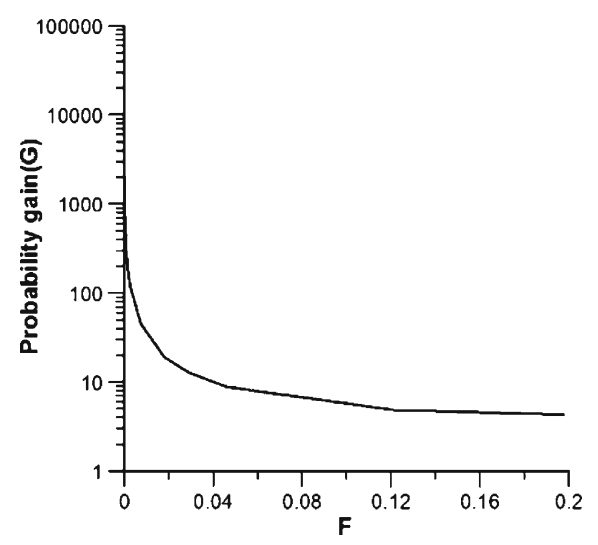

Fig. 7 As in Fig. 5, for the probability gain $G$, computed on the whole space-time volume analyzed in this study

threshold from $1.0 \mathrm{E}-07$ to $1.0 \mathrm{E}-03$ events per day per $100 \mathrm{~km}^{2}$.

Finally, for the assessment of the ETAS model performance, we have also considered the loglikelihood ratio criterion whose theory is briefly described in Appendix. As the log-likelihood ratio $(\log R)$ depends only on the probabilities in every cell of the space-time target volume, and not on the selected alarm thresholds, there is only one value obtained for this parameter, that is, $\log R=47.3$ (using natural logarithms). Therefore, the $\log R$ test confirms the superior performance of the epidemic model with respect to the timeindependent Poisson model.

\section{Discussion and conclusions}

After having demonstrated the reliability of the earthquake clustering hypothesis based on the ETAS model by forward-retrospective statistical tests, let us consider how such model yields a clear increase in the probability for an event of magnitude 5.0 or larger before the largest earthquake of a sequence in real cases.

The first case refers to the seismic sequence started on September 26th, 1997 at 00:33 UTC in Umbria-Marche region. The first mainshock of this seismic sequence (an earthquake of magnitude 5.6) exhibits a probability ratio of 4.6 times relative to the Poisson model. This is due to the influence of a few earthquakes of moderate magnitude that occurred in the same area 3 weeks 
Fig. 8 Modeled expected occurrence rate density, $M_{1} \geq 5.0$ (events per day per square kilometer) for the whole Italian territory. a On October 31, 2002 at 08:00 UTC, just ( $2 \mathrm{~h}$ ) before the strongest Molise event (5.4 $M_{1}, 10: 32$ UTC). A black star shows the epicenter (lat. $41^{\circ} .72 \mathrm{~N}$, long. $\left.14^{\circ} .89 \mathrm{E}\right)$ of the

Molise shock. b On

November 1, 2002 at 08:00 UTC, before 5.3 $M_{1}$ shock (15:09 UTC). A black star shows the epicenter (lat. $41^{\circ} .74 \mathrm{~N}$, long. $14^{\circ} .84 \mathrm{E}$ ) of the Molise shock. The occurrence probability of an $M_{1} \geq 5.0$ shock on October 31, 2002 and on November 1, 2002, inside a radius of $30 \mathrm{~km}$ centered on the Molise event, in the next $24 \mathrm{~h}$ starting from 08:00 UTC is $0.025 \%$ and $0.87 \%$, respectively

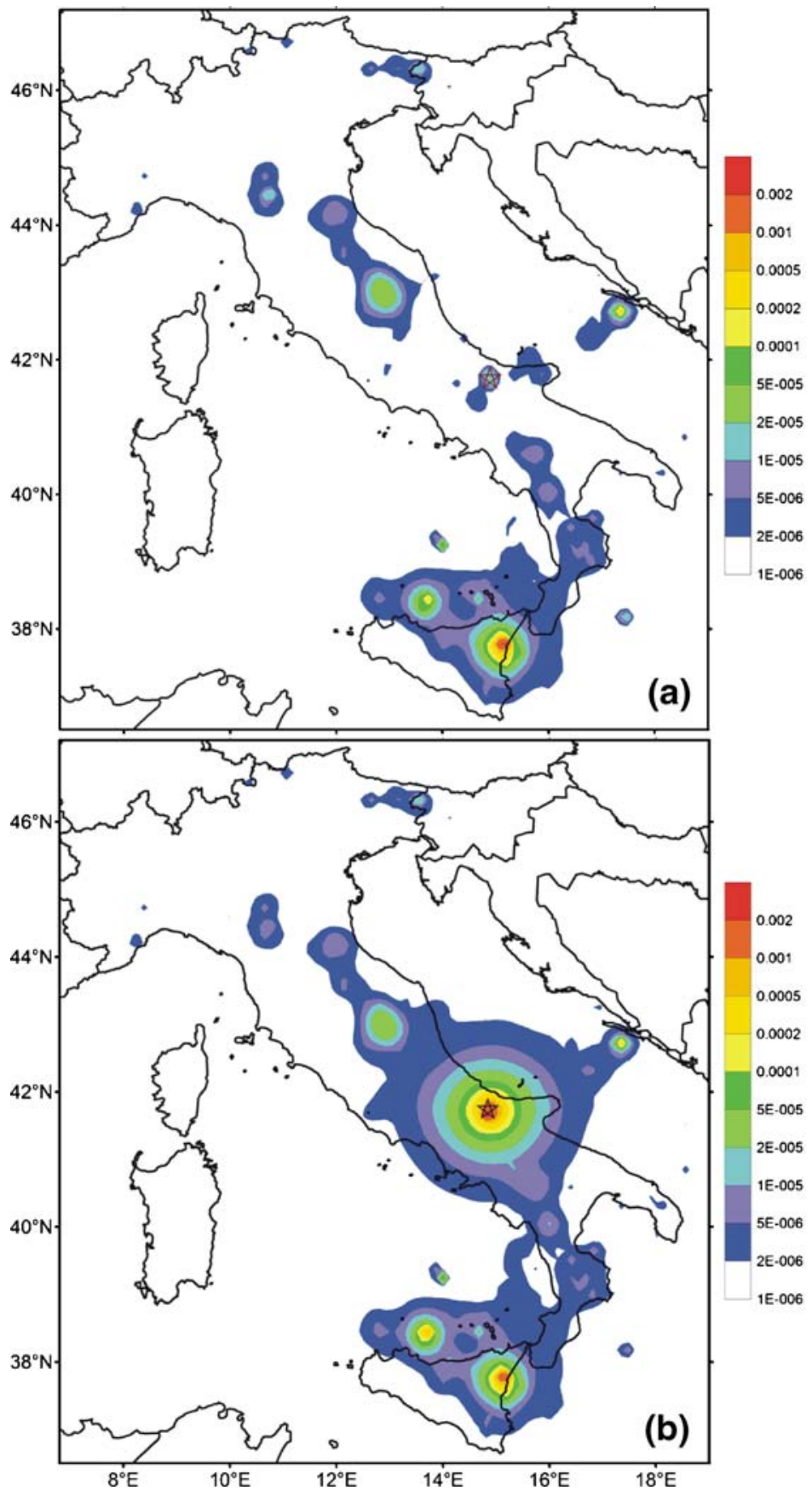

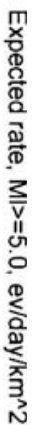

before. The strongest mainshock of magnitude 5.8, which occurred about $9 \mathrm{~h}$ later, was marked by a probability gain of 625 . This shock caused the death of four people that were surveying the damage caused by the previous mainshock to the San Francesco church in Assisi.
For the first mainshock of the Molise sequence that occurred on 31 October at 10:31 UTC $(M=$ 5.4 ), the probability ratio was equal to 50 due to the effect of a few moderate foreshocks that occurred during the previous night. The following mainshock of the 1st of November at 15:09 UTC 
( $M=5.3$ ) was characterized by a probability gain of 1,450 .

This second mainshock did not cause casualties, while the first mainshock had killed 26 children, their teacher, and other two people in the elementary school of S. Giuliano di Puglia town.

Finally, in the sequence of earthquakes started on March 27th, 2003 at 16:10 UTC, the mainshock of $M=5.9$ occurring about 2 days later was characterized by a probability gain of 4,900 .

Figure $8 \mathrm{a}, \mathrm{b}$ shows two examples of how the ETAS model could have been applied in real cases to display the spatial changes of the expected occurrence rate density before the two largest shocks of the October-November 2002 Molise sequence in southern Italy. The parameter values used in this case are reported in line 13 of Table 1 for the learning period July 1987-December 2001. Figure 8a shows the situation on October 31, 2002 at 08:00 UTC just ( $2 \mathrm{~h}$ ) before the largest mainshock of October 31 (5.4 $M_{1}, 10: 32$ UTC), the epicenter of which is indicated by a red star. The occurrence rate density before this event, ranging from $1 \mathrm{E}-005$ to $2 \mathrm{E}-005$ events per square kilometer per day, is higher than the reference seismicity rate because of precursory activity recorded during the previous night, with the largest foreshock (3.2 $M_{1}$ ) occurring at 02:27 UTC on October 31, 2002. Figure $8 \mathrm{~b}$ is a snapshot taken at $08: 00$ on November 1, 2002. This figure shows the changes in the expected occurrence rate density after the mainshock of October 31, 2002 (5.4 $M_{1}, 10: 32$ UTC) but before the November 1, 2002 Molise second mainshock (5.3 $M_{1}, 15: 08$ UTC). At this time, the occurence rate density is remarkably higher, ranging between 0.001 and $0.003\left(\mathrm{~km}^{-2}\right.$ day $^{-1}$ ).

The occurrence probability of an $M_{1} \geq 5.0$ shock, inside a radius of $30 \mathrm{~km}$ centered on the Molise $\left(5.4 M_{1}\right)$ event of October 31,2002 , in the $24 \mathrm{~h}$ following 08:00 UTC is $0.025 \%$ (line 20 in Table 2). The probability of a future shock $\left(M_{1} \geq 5.0\right)$ in $24 \mathrm{~h}$, caused by the stress changes associated with the previous events at 08:00 on November 1, 2002 estimated before the $5.3 M_{1}$ earthquake (15:08 UTC), increases to $0.87 \%$ (Fig. $8 \mathrm{~b}$ and Table 2). Extending the alarm period to 1 week, these two probabilities would increase to $0.05 \%$ and $2.33 \%$, respectively.
It could be questionable if a probability of the order of $0.1 \%$ for the occurrence of an $M_{1} \geq 5.0$ earthquake in 1 week (even if it represents an increase of about 50 times with respect to the probability associated to the reference seismicity rate for the same area) would be a reasonable threshold for issuing a warning to the population of a fairly large area. It would surely not be enough for taking mitigation measures such as evacuating the area. In fact, as shown in the previous section, such a threshold would imply issuing a large number of false alarms. Even if similar questions have social and economic implications that are beyond the purposes of this study, we may consider that a probability of the order of $0.1 \%$, that some circumstances had negative consequences for our own safeness would suggest to everybody to avoid such circumstances.

Results of this kind cannot be defined as "predictions," which are usually specified as deterministic or quasi-deterministic statements, implying considerably higher probability and more certainty than our synoptic forecasts. However, it has been widely recognized that earthquake forecasts based on statistical methodologies can be implemented and used to provide useful results (Gerstenberger et al. 2005). In the recent years, several seismological centers have implemented testing centers for evaluating probabilistic realtime forecast methods. In a similar way, starting on January 2006, our algorithm based on the ETAS model has been implemented for testing and evaluation purposes for generating automatic real-time forecasts in the INGV seismological observation center (Murru et al. 2008). In this respect, our study can be considered a contribution in the frame of the concept defined by Jordan (2006) with the term of "brick-to-brick" approach, which is nowadays broadly supported in the community of statistical seismologists (Hauksson et al. 2007).

It is easy to conclude that it will require still long time and a lot of efforts before statistical forecasts can be applied in real circumstances. These methods are characterized by a trade-off between the rate of missed alarms and the rate of false alarms, an issue that would constitute serious problems to decision makers that would try to make use of the information that they 
provide. A possible direction for further investigations could be in the synergy between shortterm statistical forecasting, such as that based on the ETAS model, and other kinds of statistical or physical intermediate-term forecasts methods, which would focus on more narrow geographical areas where a suspected earthquake might be preparing. In fact, many studies (e.g., Aki 1981; Rhoades and Evison 1989; Imoto 2007, among others) have concluded that the combination of different forecasting methods, each of which is characterized by a different probability gain and based on independent phenomena, might achieve a significantly higher joint probability gain.

Acknowledgements This work was partially supported for the years 2005-2007 by the Project S2-Assessing the seismogenic potential and the probability of strong earthquakes in Italy (Slejko and Valensise coord.)-S2 Project has benefited from funding provided by the Italian Presidenza del Consiglio dei Ministri-Dipartimento della Protezione Civile (DPC). Scientific papers funded by DPC do not represent its official opinion and policies. The authors are grateful to the Editors, Laura Peruzza, and David Perkins, and to two anonymous reviewers, for their comments and suggestions that contributed to a significant improvement of the paper.

\section{Appendix}

In this appendix, we give a short outline of four statistical algorithms used for assessing the validity of forecast hypotheses.

\section{ROC diagrams}

The relative operating characteristic (ROC) approach has been widely used for forecast verification in the atmospheric sciences, where the success rate of an event prediction is compared against the false alarm rate. ROC diagrams have already been used to evaluate earthquake prediction algorithms. Recently, Holliday et al. (2005), McGuire et al. (2005), Kossobokov (2006), Baiesi (2006), Chen et al. (2006), Zechar and Jordan (2007) among others have applied this method for this purpose.

This approach requires that a prediction of "occurrence" or "non occurrence" for the considered class of events is issued in any of the possible cells in which the whole space-time volume is divided. It is an intrinsically binary approach, by which each prediction has two possible ("true" or "false") outcomes allowing the preparation of a $2 \times 2$ contingency table summarizing the result of the specific test.

Contingency table

\begin{tabular}{lll}
\hline & Observed & \\
\hline Forecast & Yes & No \\
Yes & $a$ & $b$ \\
No & $d$ & $c$ \\
\hline
\end{tabular}

The entries for classifying the results in a $2 \times 2$ table, reading clockwise from the top left corner are the following:

$a$ number of successful forecasts of occurrence

$b$ number of false alarms

$c$ number of successful forecasts of nonoccurrence

$d$ number of failures to predict

These entries comply with the following constraints: $a+b$

$a+d$

$b+c$

$c+d$

$\mathrm{e}=a+b+c+d$ total number of cells containing alarms

total number of cells containing events really occurred total number of cells without any occurred events total number of cells without any alarms

total number of geographic cells multiplied by the number of time bins
Following the terminology introduced by Holliday et al. (2005), we make use of the parameters Hit rate $(H)$ and False alarm rate $(F)$, defined as:

$H=a /(a+d) \quad$ (fraction of events that occur on an alarm cell)

$F=b /(b+c) \quad$ (fraction of false alarms issued where an event has not occurred) 
The meaning of $H$ corresponds to that of the Reliability (Matthews and Reasenberg 1988; Rhoades and Evison 1989) that is the probability that an event is preceded by a warning.

In case the prediction algorithm is expressed in terms of probabilities (or expected rates) as for our ETAS model, it is necessary to transform the probability forecasts into binary predictions defined by some probability threshold. The result of the test produces a single point on the ROC diagram. For different thresholds the corresponding hit rates and false alarm rates can be computed. Applied to earthquake forecasting, a ROC diagram is a plot of the hit rate $H$ (the fraction of "hotspot" cells that have an earthquake forecast over the total number of cells with actual earthquakes) versus the false alarm rate $F$ (the fraction of the forecast cells that don't have earthquakes over the total number of cells with no actual earthquakes in them). In the case of purely random forecasts, $H=1-F$, and the diagram consists of the diagonal joining the points $(0,0)$ and $(0,1)$.

\section{R-score}

A test statistic, commonly called the $R$-score, can be derived from a $2 \times 2$ contingency table. The $R$-score is defined as (Shi et al. 2001):

$R=\mathrm{a} /(\mathrm{a}+\mathrm{d})-\mathrm{b} /(\mathrm{b}+\mathrm{c})$ (number of cells in which earthquakes are successfully predicted/total number of cells in which earthquakes occur) - (number of cells with false alarms/total number of cells without any earthquakes).

$R$ varies between -1 and 1 with the following meanings:

$R=-1 \quad$ all prediction are wrong.

$R \approx 0 \quad$ random prediction scores.

$R=1 \quad$ all positive and negative prediction are correct, no false alarm and no missed alarm.

A meaningful prediction must have $R>0$. A significant prediction needs $R$ larger than a marginal level.
Probability gain

We also consider the probability gain $G$ as a function of false alarm rate $F$ to measure the effectiveness of the prediction technique. This parameter was defined by Aki (1981) as the ratio between the conditional and the unconditional rate, namely:

$$
\begin{aligned}
G & =a /(a+d) \cdot e /(a+b)=H \cdot e /(a+b) \\
& =\text { Success rate/ average rate of occurrence }
\end{aligned}
$$

(or in other words the ratio between the conditional probability, success rate, and the unconditional probability, average rate or frequency of occurrence). $G$ varies between 0 and $\infty$.

Of course a relationship exists between $G$ and $R$ : when $G$ tends to $\infty, R$ goes to 1 , when $G=1 R$ is equal to 0 and when $G=0 R=-1$.

\section{Log-likelihood ratio}

Let's imagine the forecasting target volume subdivided in non-overlapping sub-volumes, or cells, that fill it completely. We may imagine that the subdivision is made on the geographical extension only, as in the method for evaluating forecasts introduced by Kagan and Jackson (1995), or on the time dimension only, or that it extends also to time or magnitude intervals, in the more general way applied in our study. This method requires that for each sub-volume $i=1, \ldots, P$ the probability $p_{i}$ of occurrence of at least one target event be estimated. After a suitable period of observation, a number $N$ of target events will have really occurred in some of the sub-volumes denoted by $j=1, \ldots, N$. Let $c_{i}=0$ denote the cells in which no events have been observed, and $c_{i}=$ 1 those in which at least one event has occurred. It can be demonstrated by means of the theory of probabilities that the log-likelihood of observing that particular realisation of the earthquake process under the hypothesis defining the probabilities $p_{i}$ is:

$\log L=\sum_{i=1}^{P}\left[c_{i} \log \left(p_{i}\right)+\left(1-c_{i}\right) \log \left(1-p_{i}\right)\right]$. 
The first term in the square brackets derives from the probability of occurrence of a target event in the cell $i$, the second derives from the probability of non-occurrence of such event in the same cell. With a slight modification, equation (7) can be also written as:

$$
\log L=\sum_{i=1}^{P}\left[c_{i} \log \left(\frac{p_{i}}{1-p_{i}}\right)+\log \left(1-p_{i}\right)\right] .
$$

It should be noted that only the first term of the latter expression under the sum depends on the actual realisation of successes, while the second one is a constant that depends on the probabilities provided by the considered model. The first term, that depends on the result of each test, is positive when the success is obtained for a test to which we assigned a probability $p_{i}$ larger than 0.5 , and negative in the contrary case. The circumstance of an event occurred in a cell to which zero probability had been assigned, leads to a value of $L$ equal to 0 and that of $\log L$ to $-\infty$ : it must be avoided in practice by imposing a minimum threshold to the occurrence rate density in the time-independent distribution.

The comparison between two $L$ functions is generally carried out taking one of them as reference (null hypothesis), defined in an appropriate way. The problem of setting up a reference hypothesis in the context of earthquake forecasting is not trivial. As an example adopted in this study, a null hypothesis could be that of a rate density distribution that depends only on space and magnitude, but not on time, for which a uniform Poisson distribution is assumed.

Naming by $p_{i}$ and $p_{0 i}$ the probabilities of occurrence of at least one event in the ith cell under the "new" and null hypothesis respectively, and with $L$ and $L_{0}$ their likelihoods, we infer, from (8):

$$
\begin{aligned}
\log R & =\log \left(\frac{L}{L_{0}}\right)=\log (L)-\log \left(L_{0}\right) \\
& =\sum_{i=1}^{P}\left[c_{i} \log \frac{p_{i}\left(1-p_{0 i}\right)}{p_{0 i}\left(1-p_{i}\right)}+\log \frac{1-p_{i}}{1-p_{0 i}}\right] .
\end{aligned}
$$

\section{References}

Aki K (1981) A probabilistic synthesis of precursory phenomena. In: Simpson DW, Richards PG (eds) Earthquake prediction. Am. Geophys. Union, Washington, pp 556-574

Baiesi M (2006) Scaling and precursor motifs in earthquake networks. Physica A 360(2):534-542

Catalli F, Cocco M, Console R, Chiaraluce L (2008) Modeling seismicity rate changes during the 1997 UmbriaMarche sequence (central Italy) through a rate-and state-dependent model. J Geophys Res 113:B11301. doi:10.1029/2007JB005356

Chen C-C, Rundle JB, Li H-C, Holliday JR, Nanjo KZ, Turcotte DL, Tiampo KF (2006) From tornados to earthquakes: forecast verification for binary events applied to the 1999 Chi-Chi, Taiwan, Earthquake. Terr Atmos Ovean Sci 17(3):503-516

Chiarabba C, Jovane L, Di Stefano R (2005) A new view of Italian seismicity using 20 years of instrumental recordings. Tectonophysics 395(3-4):251268. http://legacy.ingv.it/CSI. doi:10.1016/j.tecto.2004. 09.013

Console R (2001) Testing earthquake forecast hypotheses. Tectonophysics 338:261-268. doi:10.1016/S0040-1951 (01)00081-6

Console R, Murru M (2001) A simple and testable model for earthquake clustering. J Geophys Res 106:8699_ 8711. doi:10.1029/2000JB900269

Console R, Murru M, Lombardi AM (2003) Refining earthquake clustering models. J Geophys Res 108:2468. doi:10.1029/2002JB002130

Console R, Murru M, Catalli F (2006a) Physical and stochastic models of earthquake clustering. Tectonophysics 417:141-153. doi:10.1016/j.tecto.2005.05.052

Console R, Rhoades DA, Murru M, Evison FF, Papadimitriou EE, Karakostas VG (2006b) Comparative performance of time-invariant, long-range and short-range forecasting models on the earthquake catalogue of Greece. J Geophys Res 111:B09304. doi:10.1029/2005JB004113

Console R, Murru M, Catalli F, Falcone G (2007) Real time forecasts through an earthquake clustering model constrained by the rate-and-state constitutive law: comparison with a purely stochastic ETAS model. Seismol Res Lett 78:49-56. doi:10.1785/gssrl.78.1.49

Dieterich JH (1994) A constitutive law for rate of earthquake production and its application to earthquake clustering. J Geophys Res 99(18):2601-2618. doi:10.1029/93JB02581

Felzer KR, Becker TW, Abercrombie RE, Ekstrom G, Rice JR (2002) Triggering of the $1999 \mathrm{Mw} 7.1 \mathrm{Hec}-$ tor Mine earthquake by aftershocks of the $1992 \mathrm{Mw}$ 7.3 Landers earthquake. J Geophys Res 107(B9):2190. doi:10.1029/2001JB000911.2002

Frankel A (1995) Mapping seismic hazard in the central and eastern United States. Seismol Res Lett 66: $8-21$ 
Gerstenberger MC, Wiemer S, Jones LM, Reasenberg PA (2005) Real-time forecasts of tomorrow's earthquakes in California. Nature 435:328-331. doi:10.1038/ nature 03622

Gomberg J, Beeler NM, Blanpied ML (2000) On ratestate and Coulomb failure models. J Geophys Res 105(14):7857-7872. doi:10.1029/1999JB900438

Harris RA, Simpson RW (1998) Suppression of large earthquakes by stress shadows: a comparison of Coulomb and rate-and-state failure. J Geophys Res 103:24439-24451. doi:10.1029/98JB00793

Hauksson E, Cocco M, Console R, Wiemer S (2007) Advancing the frontiers of earthquake science. EOS 88(30):302

Helmestetter A, Shaw BE (2006) Relation between stress heterogeneity and aftershock rate in the rate-andstate model. J Geophys Res 111(B07304). doi:101029/ 2005JB004077

Helmstetter A, Sornette D (2002) Subcritical and supercritical regimes in epidemic models o earthquake aftershocks. J Geophys Res 107(B10):2237. doi:10. 1029/2001JB001580

Helmstetter A, Sornette D (2003) Predictability in the epidemic-type aftershock sequence model of interacting triggered seismicity. J Geophys Res 108(B10): 2482. doi:10.1029/2003JB002485

Holliday JR, Nanjo KZ, Tiampo KF, Rundle JB, Turcotte DL (2005) Earthquake forecasting and its verification. Nonlinear Process Geophys 12:965-977

Imoto M (2007) Information gain of a model based on multidisciplinary observations with correlations. J Geophys Res 112:B05306. doi:10.1029/2006JB004662

INGV (2007) Italian seismic bulletin. Istituto Nazionale di Geofisica e Vulcanologia. http://legacy.ingv.it/ roma/ reti/rms/bollettino/index.php

Jordan TH (2006) Earthquake probability, brick by brick. Seismol Res Lett 77(1):3-6. doi:10.1785/gssrl.77.1.3

Kagan YY (1991) Likelihood analysis of earthquake catalogues. Geophys J Int 106:135-148. doi:10.1111/j. 1365-246X.1991.tb04607.x

Kagan YY (2002) Aftershock zone scaling. Bull Seismol Soc Am 92(2):641-655. doi:10.1785/0120010172

Kagan YY (2007) On earthquake predictability measurement: information score and error diagram. Pure Appl Geophys 164:1947-1962. doi:10.1007/s00024007-0260-1

Kagan YY, Jackson DD (1995) New seismic gap hypothesis, Five years later. J Geophys Res 100:3943-3959. doi:10.1029/94JB03014

Kilb D, Gomberg J, Bodin P (2002) Aftershocks triggering by complete Coulomb stress changes. J Geophys Res 107. doi:10.1029/2001JB0002002

King GCP, Cocco M (2001) Fault interaction by elastic stress changes: new clues from earthquake sequences. Adv Geophys 44:1-39

King GCP, Stein R, Lin J (1994) Static stress change and the triggering of earthquakes. Bull Seismol Soc Am 84:935-953

Kossobokov VG (2006) Testing earthquake prediction methods: the West Pacific short-term forecast of earthquakes with magnitude $\mathrm{M}_{\mathrm{w}} \mathrm{HRV} \geq 5.8$. Tectonophysics 413(1-2):25-31. doi:10.1016/j.tecto. 2005.10.006

Ma L, Zhuang J (2001) Relative Quiescence within the Jiashi Swarm in Xinjiang, China: an application of the ETAS point process model. J Appl Probab 38:213-221 (Probability, Statistics and Seismology)

Marsan D (2006) Can coseismic stress variability suppress seismicity shadows? Insights from a rate-andstate friction model. J Geophys Res 111(B10):6305. doi:10.1029/2005JB004060

Matthews MM, Reasenberg PP (1988) Statistical methods for investigating quiescence and other temporal seismicity patterns. Pure Appl Geophys 126:2-4, 357-372. doi:10.1007/BF00879003

McGuire JJ, Boettcher MS, Jordan TH (2005) Foreshock sequences and short-term earthquake predictability on East Pacific Rise transform faults. Nature 434(7032):457-461, Correction-Nature 435(7041):528

Murru M, Console R, Falcone G (2008) Real-time earthquake forecasting in Italy. Tectonophysics. doi:10. 1016/j.tecto.2008.090.010

Nostro C, Chiaraluce L, Cocco M, Baumont D, Scotti O (2005) Coulomb stress changes caused by repeated normal faulting earthquakes during the 1997 UmbriaMarche (central Italy) seismic sequence. J Geophys Res 110(B05S20). doi:10.1029/2004JB003386

Ogata Y (1983) Estimation of the parameters in the modified Omori formula for aftershock frequencies by the maximum likelihood procedure. J Phys Earth 31: $115-124$

Ogata Y (1998) Space-time point-process models for earthquake occurrences. Ann Inst Stat Math 50(2): 379-402. doi:10.1023/A:1003403601725

Ogata Y (2001) Increased probability of large earthquakes near aftershock regions with relative quiescence. J Geophys Res 106(B5):8729-8744. doi:10. 1029/2000JB900400

Ogata Y (2004a) Space-time model for regional seismicity and detection of crustal stress changes. J Geophys Res 109(B3):B03308. doi:10.1029/2003JB002621

Ogata Y (2004b) Seismicity quiescence and activation in western Japan associated with the 1944 and 1946 great earthquakes near the Nankai trough. J Geophys Res 109(B4):B04305. doi:10.1029/2003JB002634

Ogata Y (2005) Synchronous seismicity changes in and around the northern Japan preceding the 2003 Tokachi-oki earthquake of M8.0. J Geophys Res 110(B5):B08305. doi:10.1029/2004JB003323

Ogata Y (2006a) Monitoring of anomaly in the aftershock sequence of the 2005 earthquake of M7.0 off coast of the western Fukuoka, Japan, by the ETAS model. Geoph Res Lett 33(1):L01303. doi:10. 1029/2005GL024405

Ogata Y (2006b) Seismicity anomaly scenario prior to the major recurrent earthquakes off the east coast of Miyagi Prefecture, northern Japan. Tectonophysics 424:291-306. doi:10.1016/j.tecto.2006.03.038

Ogata Y (2007) Seismicity and geodetic anomalies in a wide area preceding the Niigata-Ken-Chuetsu 
earthquake of 23 October 2004, central Japan. J Geophys Res 112:B10301. doi:10.1029/2006JB004697

Ogata Y, Katsura K (1993) Analysis of temporal and spatial heterogeneity of magnitude frequency distribution inferred from earthquake catalogues. Geophys J Int 113:727-738. doi:10.1111/j.1365-246X.1993. tb04663.x

Ogata Y, Katsura K (2006) Immediate and updated forecasting of aftershock hazard. Geophys Res Lett 33(10):L10305. doi:10.1029/2006GL025888

Ogata Y, Zhuang J (2006) Space-time ETAS models and an improved extension. Tectonophysics 413:1323. doi:10.1016/j.tecto.2005.10.016

Ogata Y, Jones LM, Toda S (2003) When and where the aftershock activity was depressed: contrasting decay patterns of the proximate large earthquakes in southern California. J Geophys Res 108(B6):2318. doi:10.1029/2002JB002009 (1-12)

Parsons $\mathrm{T}$ (2004) Recalculated probability of $\mathrm{M} \geq 7$ earthquakes beneath the Sea of Marmara, Turkey. J Geophys Res 109:B05304. doi:10.129/2003JB002667

Parsons T, Dreger DS (2000) Static-stress impact of the 1992 landers earthquake sequence on nucleation andslip at the site of the $1999 \mathrm{M}=7.1$ Hector Mine earthquake, southern California. Geophys Res Lett 27:1949-1952. doi:10.1029/1999GL011272

Rhoades DA, Evison FF (1989) On the reliability of precursors. Ph Earth Plann Int 58:137-140. doi:10.1016/ 0031-9201(89)90049-6

Rydelek PA, Sacks IS (1989) Testing the completeness of earthquake catalogs and the hypothesis of self-similarity. Nature 337:251-253. doi:10.1038/ $337251 \mathrm{a} 0$

Saichev A, Sornette D (2006) Renormalization of branching models of triggered seismicity from total to observable seismicity. Eur Phys J B 51:443-459. doi:10. 1140/epjb/e2006-00242-6

Shi Y, Bolt B (1982) The standard error of the magnitude frequency b value. Bull Seismol Soc Am 72:16771687

Shi Y, Liu J, Zhang G (2001) An evaluation of Chinese annual earthquake predictions, 1990-1998. J Appl Probab 38A:222-231. doi:10.1239/jap/1085496604
Steacy S, Nalbant S, McCloskey J, Nostro C, Scotti O, Beaumont D (2005) Onto what planes should Coulomb stress perturbations be resolved? J Geophys Res 110(B05S15). doi:10.1029/2004JB003356

Stein RS, Barka AA, Dieterich JH (1997) Progressive failure on the North Anatolian fault since 1939 by earthquake stress triggering. Geophys J Int 128:594-604. doi:10.1111/j.1365-246X.1997.tb05321.x

S2 project (2005-2007) Evaluation of seismogenic potential and probability of large earthquakes in Italy supported for the years 2005-2007 by the Italian Department for Civil Protection (DPC) and the Istituto Nazionale di Geofisica e Vulcanologia (INGV)

Toda S, Stein RS (2003) Toggling of seismicity by the 1997 Kagoshima earthquake couplet: a demonstration of time-dependent stress transfer. J Geophys Res 109(B12, 2567). doi:10.1029/2003JB002527

Toda S, Stein RS, Richards-Dinger K, Bozkurt SB (2005) Forecasting the evolution of seismicity in southern California: animations built ion earthquakes stress transfer. J Geophys Res 110:B05S16. doi:10.1029/ 2004JB003415

Wiemer S (2001) A software package to analyze seismicity: ZMAP. Seismol Res Lett 72:373-382

Wiemer S, Benoit J (1996) Mapping the b-value anomaly at $100 \mathrm{~km}$ depth in Alaska and New Zealand subduction zones. Geophys Res Lett 23:1557-1560. doi:10.1029/96GL01233

Wiemer S, Wyss M (2000) Minimum magnitude of completeness in earthquake catalogs: examples from Alaska, the Western United States, and Japan. Bull Seism Soc Am 90:859-869

Zechar JD, Jordan TH (2007) Testing alarm-based earthquake predictions. Geophys J Int. doi:10.1111/j.1365246X.2007.03676.x

Zhuang J, Ogata Y, Vere-Jones D (2004) Analyzing earthquake clustering features by using stochastic reconstruction. J Geophys Res 109(B5):B05301. doi:10. 1029/2003JB002879

Zhuang J, Chang C, Ogata Y, Chen Y (2005) A study on the background and clustering seismicity in the Taiwan region by using point process models. J Geophys Res 110(B5):B05S18. doi:10.1029/2004JB003157 